\title{
La blogosfera política española en las Elecciones Generales 2011. Una comparación entre blogs de candidatos, periodistas y ciudadanos ${ }^{1}$
}

\section{The Spanish political blogosphere in General Election 2011. A comparative study among candidates', journalists' and citizens' blogs}

\author{
Lidia Valera. Universidad de Valencia (lidia.valera@uv.es) \\ José Gamir. Universidad de Valencia (jose.gamir@uv.es) \\ Guillermo López. Universidad de Valencia (guillermo.lopez@uv.es)
}

Recibido: 15-IV-2015 - Aceptado: 6-VIII-2015

Resumen:

El presente estudio propone un análisis de la blogosfera política española durante la campaña electoral previa a las Elecciones Generales del 20 de noviembre de 2011, con el fin de identificar los principales temas de discusión que centraron el debate en tres tipos de bitácoras: seis blogs de candidatos políticos de las principales formaciones políticas españolas, cuatro a cargo de periodistas destacados de la esfera pública central y cuatro de ciudadanos anónimos. Se plantea un análisis de contenido fundamentado en 57 categorías temáticas para establecer la composición de las agendas de los catorce bloggers y realizar una comparación entre ellas. El análisis mostrará las líneas de fuerza de las agendas de los tres actores del proceso de comunicación política-partidos políticos, medios de comunicación y ciudadanía-, así como las particularidades asociadas a los tres tipos de autoría.

Palabras clave:

Blogs políticos; campaña electoral 2011; análisis de contenido; comunicación digital; esfera pública.

Abstract:

This study constitutes and analysis of the Spanish political blogosphere during the electoral campaign of the General Election 20th November 2011, in order to identify the most debated issues in three different types of blogs: six blogs belonging to candidates of the main Spanish political forces, four blogs of well-known journalists and four blogs of anonymous citizens. We propose a content analysis based on 57 thematic categories in order to establish the agendas' composition of the fourteen bloggers and draw a comparison between them. The results will show the different agendas deployed by the three main actors of political communication processes - political parties, the news media and the citizenship- and the distinctive features associated with the three different types of authors.

Keywords:

Political blogs; electoral campaign 2011; content analysis, digital communication; public sphere.

1 Este trabajo se inscribe en el proyecto nacional de I+D “Cibercampaña, ciberperiodismo y ciberactividad del electorado” (Ministerio de Ciencia e Innovación, 2011-2013), dirigido por Víctor Sampedro Blanco (Universidad Rey Juan Carlos), y con referencia CSO2010-21799-C02-01. 


\section{Introducción}

\subsection{La aparición y el desarrollo de los blogs como herramienta de comunicación}

La expansión de los cauces tradicionales de comunicación mediática, merced a la aparición de las tecnologías digitales, ha supuesto la superación parcial de la verticalidad asociada a la comunicación de masas y la apertura de nuevas formas de participación de abajo-arriba en manos de la ciudadanía (Gibson y Römmele, 2007). Entre la pléyade de nuevas plataformas comunicativas, que han sido acogidas con entusiasmo por gran parte de la academia por su enorme potencial para democratizar la esfera pública (Rheingold, 2002; Lévy, 2004; Jenkins, 2006), destacan por su temprana creación los blogs.

En efecto, estas herramientas permiten a los usuarios producir sus propios contenidos a un coste extremadamente bajo y acceder potencialmente a una audiencia significativa. Además, los blogs posibilitan una doble bidireccionalidad: entre los propios autores, mediante los hipervínculos, y entre autores y usuarios, mediante los sistemas de comentarios (Albrecht et al., 2009). Así, las bitácoras permiten, ya desde principios del siglo XXI, expresar y distribuir información y opiniones alternativas a aquellas que circulan en el espacio público tradicional, producidas por los actores sociales hegemónicos: medios y élites políticas (Davis, 2009; Farrell et al., 2008; Maratea, 2008).

Desde entonces, la blogosfera ha ido adquiriendo relevancia en el debate de los asuntos de interés general (Drezner y Farrell, 2007), ya que en ella ha encontrado expresión el descontento de parte de la ciudadanía frente a los actores políticos, las rutinas periodísticas y el funcionamiento del sistema democrático (Jenkins, 2006: 217-219). Uno de los ejemplos clásicos de esta creciente importancia remite a la Guerra de Irak de 2003, cuando la blogosfera política norteamericana acogió la expresión de las primeras protestas contra la invasión de Irak en un contexto de gran aquiescencia entre la Administración Bush y los medios convencionales a favor de la contienda (Hennessy y Martin, 2006).

Asimismo, la blogosfera también ha asumido funciones de vigilancia y crítica de la información proporcionada por los medios tradicionales, denunciando en ocasiones la publicación de información falsa y depurando, en definitiva, el debate que se despliega en la arena mediática (Gillmor, 2004; Himmelsbach, 2005; Davis, 2009). De hecho, para algunos, los autores de estas bitácoras se han convertido en auténticos "nuevos influyentes" (Gillin, 2007), si bien en muchos casos su notoriedad social y su capacidad para convertirse en prescriptores que generan opinión, en "quinto poder" (Mazzoleni, 2010), derivan de su actividad política, periodística o social en los espacios de la comunicación tradicional (Kelly, 2008).

Esta creciente relevancia se enmarca, no obstante, en el contexto de la todavía existente hegemonía de los medios de masas, que siguen dominando la producción de los flujos informativos y de opinión merced a su mayor implantación social y sus grandes audiencias. Así lo refleja, por ejemplo, el hecho de que, pese a haber conseguido influir puntualmente 
en la agenda política y mediática, generalmente los blogs han tendido a reproducir la agenda de los medios tradicionales (Davis, 2009).

\subsection{Los blogs como instrumentos de comunicación política}

En el terreno de la política, el blog ha sido una herramienta tempranamente empleada por sus amplias posibilidades comunicativas, las nulas barreras de entrada y su potencial para movilizar a los votantes y simpatizantes (Adamic y Glance, 2005; Davis, 2009; Albrecht et al., 2009). Así lo refleja el éxito de campañas como la de Howard Dean en 2004 y la de Segolène Royal en 2007, que exhibieron un aprovechamiento destacado de esta herramienta como método de contacto permanente con las bases y como espacio de debate abierto a la ciudadanía (Jenkins, 2006; Trippi, 2008; Lilleker y Jackson, 2011).

Pero más allá de estos ejemplos, que destacan por su temprana y hábil utilización, existe abundante evidencia empírica del uso de estas herramientas en campaña en numerosos países, como Estados Unidos (Adamic y Glance, 2005; Hargittai et al, 2008), Reino Unido (Auty, 2005; Coleman y Ward, 2005; Jackson, 2006; Stanyer, 2005), Dinamarca (Klastrup y Petersen, 2007) o Alemania (Abold y Heltsche, 2006; Ott, 2006).

En España, la blogosfera política comienza a adquirir cierta relevancia con motivo de las Elecciones Legislativas de 2004, convulsas por los atentados terroristas y el clima posterior de desconcierto (Sampedro y López, 2005; López, 2006). En este sentido, diversos estudios sobre los flujos comunicativos durante los días que sucedieron a los atentados señalan cómo los blogs se convirtieron en fuentes informativas y espacios de deliberación (y también de expresión de posturas radicales) para los usuarios más activos en Internet, insatisfechos con la cobertura de los medios tradicionales, mayoritariamente alineados con la versión del Gobierno sobre la autoría del atentado (Sampedro y López, 2005; López, 2006). Pero es durante la campaña de las Elecciones Generales de 2008 cuando los actores políticos españoles exhibieron un uso más extendido de esta herramienta de comunicación como instrumento de marketing político (Peytibi et al., 2008; Dader, 2009), a pesar de que los principales candidatos a la Presidencia del Gobierno no pusieron en marcha un blog propio.

De forma paralela a esta generalización progresiva, la investigación académica ha puesto de manifiesto que la blogosfera política exhibe una notable tendencia a la fragmentación y el encapsulamiento ideológico, tal como vaticinaban algunas voces escépticas en torno al impacto de Internet en la comunicación política (Sunstein, 2001). En efecto, diversos estudios se han ocupado de cartografiar la estructura de hipervínculos que se establece en las blogosferas políticas de varios países, y sus resultados evidencian que existe una clarísima fragmentación en nichos ideológicamente homogéneos (Adamic y Glance, 2005; Stanyer, 2006; Hargittai et al., 2008; Albrecht et al., 2009; Fouetillou, 2011), de forma que la mayor parte de los blogs sólo enlazan con espacios ideológicamente afines y excluyen referencias a otro tipo de contenidos. 
Lo mismo sucede con los pocos estudios estadísticamente significativos sobre las audiencias de Internet, que revelan que los lectores de blogs son arrolladoramente partidistas, consumen blogs casi exclusivamente de su propio espectro ideológico, y están significativamente más polarizados que los consumidores de otros medios y que las propias élites políticas, pues se ubican en los extremos de sus respectivas esferas ideológicas (Farrell et al., 2008). Una línea coincidente, en líneas generales, con la tónica de consumo de información política en Internet o el activismo en torno a cuestiones políticas: son los ciudadanos más politizados -y más partidistas- los que consumen en mayor medida este tipo de contenidos, es de suponer (dados los mencionados resultados sobre la homogeneidad ideológica de la blogosfera) que fundamentalmente como una estrategia de reafirmación ideológica (véase Anduiza, Cantijoch y Cristancho, 2010, en relación con el caso español).

En España, si bien el volumen de estudios es todavía limitado, diversas investigaciones apuntan también a la parcelación de la blogosfera política española en nichos ideológicos (López y Lara, 2009; López et al., 2011), por cuanto las bitácoras tienden a incluir únicamente enlaces a webs ideológicamente afines y a excluir cualquier referencia a contenidos de otro signo ideológico. Esta fragmentación, contrariamente a lo que podría deducirse, no es privativa de los blogs periodísticos por efecto de emulación del pluralismo polarizado del sistema mediático español (Hallin y Mancini, 2004), sino que también concurre en el caso de blogs ciudadanos. Éstos últimos exhiben también un alineamiento partidista en términos de los contenidos publicados, de forma que tienden a reproducir las agendas partidistas de sus respectivas esferas ideológicas (Valera Ordaz, 2012). No obstante, otros estudios señalan que, con todo, los blogs exhiben un debate significativamente más independiente de las agendas partidistas que los medios tradicionales, mucho más temáticamente alineados con los partidos durante períodos electorales (Valera Ordaz, 2015).

Por su parte, el análisis sobre las discusiones políticas que acogen los sistemas de comentarios de los blogs, de acuerdo con diferentes variables que operacionalizan las condiciones normativas de la democracia deliberativa, muestra un panorama general que tiende al consenso ideológico. Tanto es así que las conversaciones alojadas en las bitácoras ciudadanas presentan un nivel mayor de homogeneidad ideológica que sus homólogas políticas o periodísticas (Valera Ordaz, 2014a).

En definitiva, el papel de los blogs en la esfera pública parece caracterizarse, hasta la fecha, por una notable ambivalencia (López et al., 2013). Por un lado, ensanchan el espacio público, pues facilitan la publicación de información y puntos de vista ajenos al flujo hegemónico de comunicación de masas, lo que sin duda consagra la apertura del modelo vertical de comunicación. Por otro, desarrollan principalmente "esferas públicas periféricas" (Sampedro, 2000) que en muchas ocasiones tienden a la homogeneidad, el aislamiento y la uniformidad ideológica, lo que limita sus beneficios democráticos.

\subsection{Objetivos y preguntas de investigación}

El presente estudio se propone, por lo tanto, profundizar en el conocimiento que tenemos sobre el papel que desempeñan estas herramientas comunicativas en el espacio público. Aspiramos a observar qué tipo de contenidos son abordados 
en la blogosfera política durante un proceso electoral, así como a examinar la independencia de éstos con respecto a las agendas partidistas de los principales partidos. De este modo, podremos evaluar si la blogosfera política española supone un ensanchamiento de la esfera y el debate públicos, o si, por el contrario, constituye una reproducción amplificada del flujo hegemónico de comunicación de masas.

El análisis aborda el debate acogido en la blogosfera política española durante la campaña electoral de las Elecciones Generales de 2011 mediante una triple comparación entre tres espacios: 1) blogs gestionados por candidatos políticos de los principales partidos políticos españoles, 2) bitácoras a cargo de periodistas de larga trayectoria y 3) blogs pertenecientes a ciudadanos anónimos.

Las principales preguntas de investigación que han guiado el presente trabajo son las siguientes:

1. ¿Qué clase de contenidos son sometidos a debate en los tres tipos de blogs analizados? ¿Varían los temas de debate en función de la autoría de las bitácoras o, por el contrario, todos tienden a tratar las mismas cuestiones en proporciones similares?

2. ¿Qué temas prevalecen en cada espacio? ¿Se ocupan los tres tipos de blogs en igual medida de cuestiones estrictamente relacionadas con la campaña electoral o tienden a acoger un debate más sustantivo, fundamentado en diversas áreas de política pública?

3. ¿influye la orientación ideológica de cada blog en los contenidos publicados? ¿Reproducen estos espacios las prioridades temáticas y programáticas de los partidos durante la campaña o exhiben un debate independiente?

\section{Metodología}

\subsection{Diseño metodológico}

La metodología utilizada en el presente estudio parte del clásico análisis de contenido (Krippendorf, 1990), una de las técnicas de investigación más consolidadas en el campo de la comunicación (Piñuel, 2002; Igartua y Humanes, 2004; Vicente Mariño, 2009), a través de la cual es posible analizar los mensajes comunicativos de forma sistemática, objetiva y cuantitativa (Wimmer y Dominick, 1996). En efecto, esta herramienta permite examinar el mensaje aislándolo del resto del proceso comunicativo por medio de variables de análisis generales que describen sus características. De este modo, el análisis de contenido se configura como una herramienta particularmente idónea para identificar la composición temática de las agendas de los blogs y establecer una comparación entre ellas. 
Desde un punto de vista más específico, el diseño metodológico se compone de 57 categorías temáticas que engloban el conjunto de cuestiones relevantes susceptibles de ser comentadas y debatidas durante la campaña. Esta lista de categorías incluye tanto áreas específicas de política pública (como la política exterior, el desempleo, la educación, la crisis de deuda o la política fiscal), como cuestiones relativas al propio devenir de la campaña (debates electorales, eventos de campaña, sondeos, estimación de resultados). Durante el proceso de codificación, los textos publicados por todos los blogs que componen la muestra fueron analizados a la luz de estas categorías. Concretamente, se registraron entre un mínimo de uno y un máximo de tres temas por pieza informativa, en función de la extensión del texto.

Conviene, finalmente, señalar que esta metodología cuenta ya con cierto recorrido, pues ha sido aplicada a diversas muestras de discurso político (Valera y López, 2014), mediático y de la propia blogosfera política (López y Clemente, 2010; Valera, 2012; López, Campos y Valera, 2013; Valera, 2015) durante diversos períodos temporales, en el marco de dos proyectos nacionales de I+D sucesivos.

\subsection{Corpus y marco temporal}

El marco temporal en el que se inscribe la presente investigación corresponde a la campaña electoral oficial de las Elecciones Generales de noviembre de 2011, pero incluye asimismo el día de los comicios y las dos jornadas posteriores a las elecciones (4-22 de noviembre). Esta extensión del marco temporal obedece a que las bitácoras políticas presentan un ritmo de periodicidad significativamente flexible y dispar, y no necesariamente se actualizan a diario, como ocurre en el caso de los medios tradicionales. La ampliación responde, por lo tanto, a la voluntad de incluir las últimas reflexiones de los blogs políticos con motivo de la campaña electoral y el análisis de los resultados electorales.

Por su parte, la selección de la campaña electoral como marco temporal objeto del estudio se justifica por la singular relevancia que reviste este período específico para la formación de las preferencias políticas de la ciudadanía, que trae consigo una intensificación del debate público sobre los asuntos de interés general. Un debate que se escenifica de forma simultánea en múltiples plataformas mediáticas tradicionales y digitales. Así, las campañas electorales parecen un período particularmente propicio para analizar la naturaleza y las características de la deliberación pública que se despliega en la blogosfera política.

En cuanto a la selección de blogs en sí, esta se ha llevado a cabo siguiendo diversos indicadores, con el propósito de garantizar:

Que, en primer lugar, la muestra mostrase cierta continuidad respecto del ya mencionado análisis de la blogosfera española en las Elecciones Generales de 2008 (López García, Lara y Sánchez Duarte, 2011). En dicho análisis se manejó una muestra de dieciséis blogs, similar a la actual, pero inscrita sólo en torno a dos categorías: blogs asociados 
con periodistas o medios de comunicación y blogs ciudadanos. Con vistas a realizar una comparación entre los resultados de ambas campañas, un primer criterio fue, por tanto, buscar -en la medida de lo posible, dado que algunos blogs ya habían dejado de funcionar- el mantenimiento de los blogs de 2008 en el estudio de 2011. Algo que se justifica no sólo por nuestro interés en desarrollar un estudio a largo plazo, sino porque la muestra de blogs de 2008 estuvo basada en una serie de criterios que aseguraban la importancia de las bitácoras seleccionadas (centralidad, impacto social, diversidad ideológica). Lógicamente, muchos de los blogs que eran influyentes en 2008, y que siguieron actualizando y publicando en los tres siguientes años, continuaron siéndolo en 2011.

- Que la muestra de blogs resultase relevante en términos de influencia y difusión social. Para ello, se siguió el criterio de analizar la posición de los blogs preseleccionados en los listados (por categorías) existentes en Wikio.es, un buscador de blogs que ha evolucionado a tienda online ${ }^{2}$, y que en la época de la configuración definitiva de la muestra (2011) era la referencia inexcusable en España para determinar el grado de incidencia social de cada blog en su ámbito. Los rankings venían determinados por Wikio a través de un algoritmo similar al de Google, que combinaba el criterio cuantitativo y el cualitativo. Por un lado, el número de enlaces que remitían a cada blog. Por otro, el tipo de sitios web que enlazaban.

- Que la muestra de blogs fuese, además, ideológicamente diversa. Este criterio se siguió mediante un procedimiento de selección en virtud del cual en cada categoría de blogs (partidos políticos, medios y ciudadanos) nos encontrásemos una selección que o bien abarcase distintos posicionamientos ideológicos, en torno al eje izquierda/derecha, como ocurre en los blogs periodísticos y ciudadanos (en cada caso contamos con dos blogs más cercanos a posicionamientos progresistas, y otros tantos conservadores); o bien estuviese compuesta por representantes de los principales partidos políticos con representación parlamentaria (PP, PSOE, IU, UPyD, CiU, PNV), sin perder tampoco de vista que, globalmente, constituyeran una muestra diversa en lo ideológico.

Que la muestra de blogs abarcase los tres espacios o actores de la comunicación política mencionados anteriormente: partidos políticos, medios de comunicación y ciudadanos.

Por último, lógicamente, la muestra de blogs tenía una última restricción: que los blogs publicasen algún contenido específico a lo largo de las fechas objeto de nuestro análisis. Esta última condición fue en la práctica la limitación más importante en la configuración de la muestra. En primer lugar, porque varios de los blogs analizados en 2008 ya no existían, o no se actualizaron, en la campaña de 2011. Y en segundo lugar, en lo que atañe a los blogs políticos, porque la preselección que efectuamos con algunos meses de antelación a la campaña de las Elecciones Generales de 2011 se desveló después muy poco operativa, por exactamente la misma razón: la mayoría de los blogs

El testigo de Wikio, desde la perspectiva de elaborar rankings de blogs, ha sido tomado por la web http://es.labs.teads.tv/top-blogs 
de dirigentes políticos preseleccionados (en concreto, los de Ana Mato, Elena Valenciano, Gaspar Llamazares y Rosa Díez) no publicaron durante la campaña, e incluso -en algún caso- cerraron su blog. Por esta razón, no tuvimos más remedio que realizar, en el caso específico de los blogs de candidatos, una profunda actualización de la muestra $a$ posteriori, esto es: una vez finalizada la campaña electoral (que, por otra parte, nos confirió la ventaja de poder observar la tasa de actividad de cada blog en su conjunto).

De este modo, la muestra de blogs definitiva, y que conforma el corpus de análisis de la presente investigación, es la siguiente (se destacan, en cursiva, los blogs que ya formaron parte del estudio de 2008):

Periodistas

- $\quad$ Escolar.net 3 : Blog del periodista Ignacio Escolar (actualmente director del ElDiario.es)

- $\quad$ El blog de Federico": Blog del editor de Libertad Digital, Federico Jiménez Losantos

- $\quad$ Punto de vista ${ }^{5}$ : Blog del exdirector de El País, Jesús Ceberio, activado específicamente para el seguimiento de la campaña electoral

- $\quad$ El Mundo por dentro y por fuera ${ }^{6}$ : Blog del periodista del diario El Mundo Arcadi Espada

\section{Políticos}

- $\quad$ Dolores de Cospedal $(\mathrm{PP})^{7}$

- $\quad$ Leire Pajín (PSOE) ${ }^{8}$

- $\quad$ Carlos Martínez Gorriarán (UPyD) ${ }^{9}$

- $\quad$ Josep Antoni Duran i Lleida $(\mathrm{CiU})^{10}$

- $\quad$ Iñaki Anasagasti (PNV) ${ }^{11}$

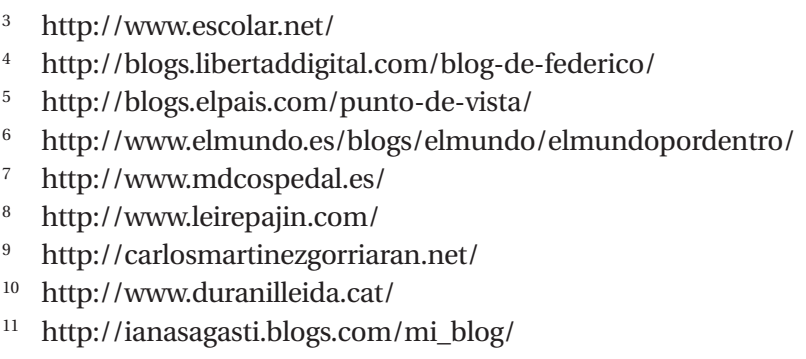


- $\quad$ Joan Josep Nuet (IU) ${ }^{12}$

\section{Ciudadanos}

- $\quad$ Punts de vista ${ }^{13}$ : Blog de Àngels M. Castells, publicado en catalán, y ubicado en la izquierda política, como puede verse en la presentación del blog en la cabecera del blog: “dona, d'esquerres, economista i moltes coses més”

- $\quad$ Materias grises ${ }^{14}$ : Blog de Roger Senserrich, militante del PSOE. El blog se integraría paulatinamente en el blog colectivo Politikon

- $\quad$ Batiburrillo ${ }^{15}$ : blog colectivo de ideología conservadora, inicialmente integrado en la red liberal-conservadora "Red Liberal"

- $\quad$ Desde el exilio ${ }^{16}$ : Blog similar al anterior en su posicionamiento ideológico, aunque con mayor dispersión temática en cuestiones no relacionadas específicamente con la actualidad política.

12 http://www.nuet.cat/

13 http://puntsdevista.wordpress.com/

14 http://politikon.es/materiasgrises/

$15 \mathrm{http} / / /$ batiburrillo.redliberal.com/

16 http://www.desdeelexilio.com/ 
Tabla 1: Composición de la muestra de blogs

\begin{tabular}{|l|l|c|}
\hline Título del blog & Dominio web & No artículos \\
\hline Escolar.net & http://www.escolar.net/ & 19 \\
\hline El blog de Federico & http://blogs.libertaddigital.com/blog-de-federico/ & 2 \\
\hline Punto de vista & http://blogs.elpais.com/punto-de-vista/ & 18 \\
\hline El Mundo por dentro y por fuera & http://www.elmundo.es/blogs/elmundo/elmundopordentro/ & 12 \\
\hline Materias grises & http://politikon.es/ & 9 \\
\hline Desde el exilio & http://www.desdeelexilio.com/ & 6 \\
\hline Punts de vista & http://puntsdevista.wordpress.com/ & 9 \\
\hline Batiburrillo & http://batiburrillo.redliberal.com/ & 7 \\
\hline María Dolores Cospedal & http://www.mdcospedal.es/ & 3 \\
\hline Blog de Leire Pajín & http://www.leirepajin.com/ & 22 \\
\hline El blog de Carlos Martínez Gorriarán & http://carlosmartinezgorriaran.net/ & 3 \\
\hline Duran i Lleida Blog & http://www.duranilleida.cat/ & 3 \\
\hline Iñaki Anasagasti & http://ianasagasti.blogs.com/mi_blog/ & 38 \\
\hline El bloc de Joan Josep Nuet & http://www.nuet.cat/ & 14 \\
\hline Total & & 165 \\
\hline
\end{tabular}

Fuente: Elaboración propia

\section{Resultados}

La sección de resultados se estructura en tres partes. Cada una de ellas recoge los resultados de las agendas temáticas de los blogs analizados en función de su autoría: 1) candidatos políticos, 2) periodistas y 3) ciudadanos anónimos.

\subsection{Los blogs de candidatos políticos}

El blog de la secretaria general del Partido Popular y presidenta de Castilla-La Mancha, María Dolores de Cospedal, combina a partes iguales temas relacionados con asuntos públicos y temas estrictamente vinculados con la campaña electoral como acontecimiento político. Así, Cospedal se ocupa primordialmente de asuntos económicos como el desempleo (25\%), los impuestos (12,5\%) y la crisis de la deuda (12,5\%), tres de los temas con mayor presencia en la agenda del Partido Popular tanto durante la precampaña y campaña electoral (Valera y López, 2014) como durante la IX Legislatura. Esta 
centralidad de las cuestiones económicas revela la estrategia electoral del Partido Popular durante la campaña, fuertemente centrada en la crisis económica, el desempleo y la gestión socialista de Zapatero.

Cuadro 1: La agenda del blog María Dolores Cospedal (N=3)

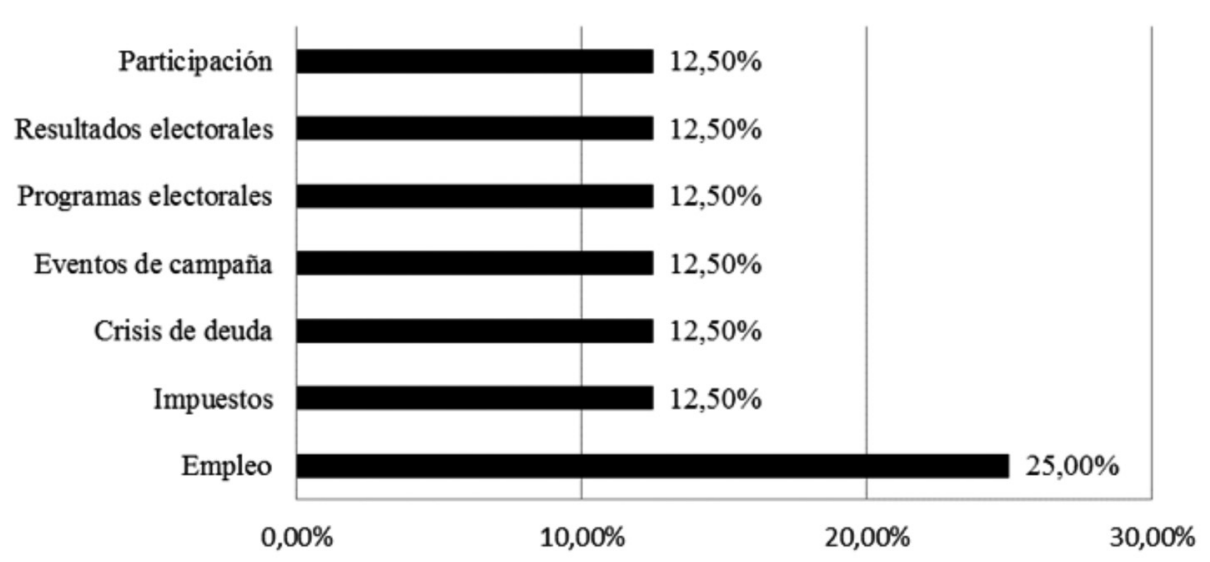

Fuente: Elaboración propia

En lo referente a aspectos específicamente relacionados con la campaña electoral, el blog concede un tratamiento similar a eventos (12,5\%), programas electorales (12,5\%), estimación de resultados (12,5\%) y llamamiento a la participación $(12,5 \%)$. Sin embargo, es necesario relativizar el alcance de los resultados obtenidos como consecuencia del reducido tamaño de la muestra, pues la autora sólo publicó tres artículos durante el periodo analizado.

El blog de Leire Pajín, ex secretaria de Organización del PSOE y entonces ministra de Sanidad, Política Social e Igualdad, concede mayor atención a los asuntos relacionados con la campaña (69,44\%) que a los referidos a políticas públicas específicas (30,56\%). Entre los primeros, el Blog de Leire Pajín se ocupa del estímulo de la participación (2,78\%), los debates electorales $(2,78 \%)$, los programas electorales $(8,33 \%)$ y, sobre todo, de los eventos de campaña $(55,56 \%)$ protagonizados por la propia autora en su condición de cabeza de lista del PSOE al Congreso de los Diputados por la provincia de Alicante. De hecho, el blog de Pajín presenta un sesgo notable en este sentido, por cuanto más de la mitad de los artículos se centran en los eventos de campaña de la autora, el mayor porcentaje registrado por dicho ítem entre los blogs de candidatos analizados.

En cuanto a los asuntos públicos, los temas presentes en la agenda de Pajín coinciden plenamente con los presentes en la agenda de su partido (Valera y López, 2014), al destacar los recortes económicos y sociales (2,78\%) y otras cuestiones económicas (8,33\%), así como dos asuntos característicos de la esfera ideológica progresista: la sanidad (5,56\%) y la ley del 
aborto $(2,78 \%)$, propios además de las competencias del Ministerio que dirigía. Sólo la alusión del Plan Hidrológico Nacional $(2,78 \%)$, un aspecto especialmente presente en la agenda política de la provincia por la que se presenta, no guarda relación directa con los ejes temáticos generales de la campaña del PSOE.

Cuadro 2: La agenda del Blog de Leire Pajín (N=22)

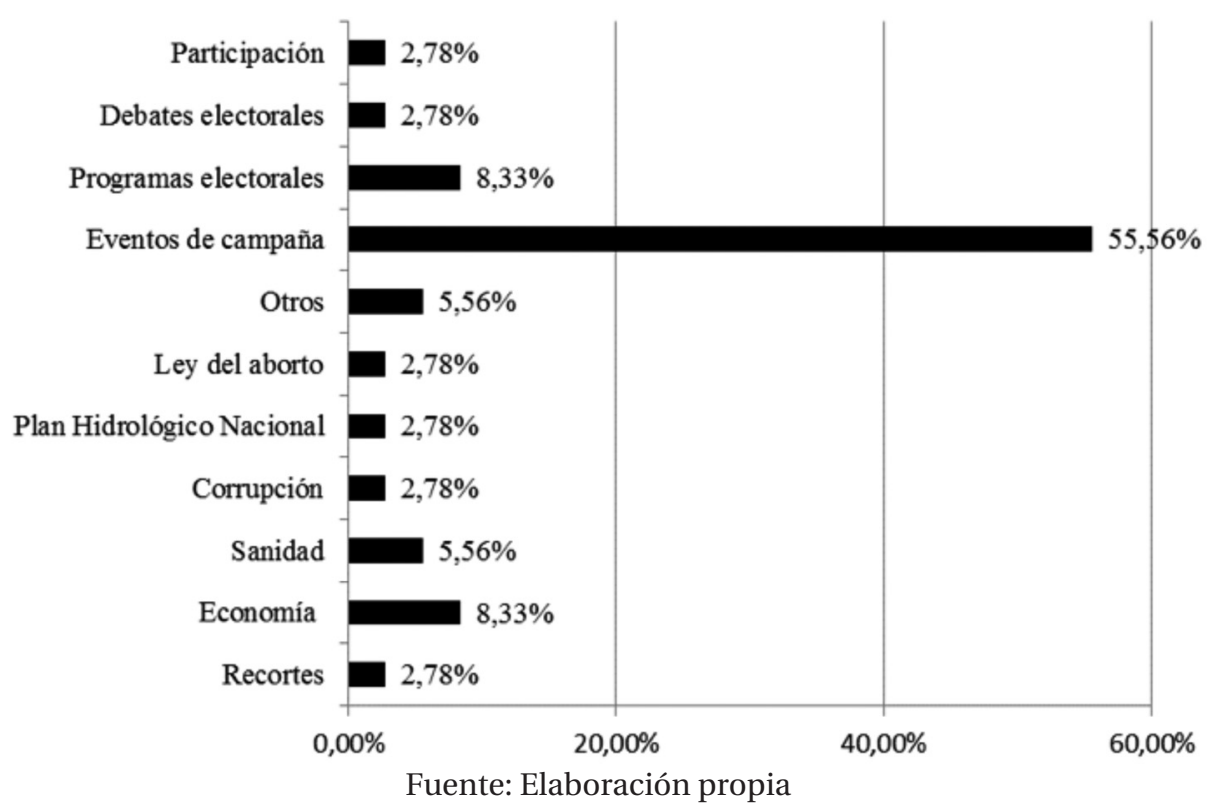

La bitácora de Josep Antoni Duran i Lleida, presidente de Unió Democrática de Catalunya, entonces secretario general de Convergencia i Unió y cabeza de lista de la federación nacionalista al Congreso de los Diputados por la provincia de Barcelona, registró una actividad escasa durante el periodo analizado, con sólo tres publicaciones. 


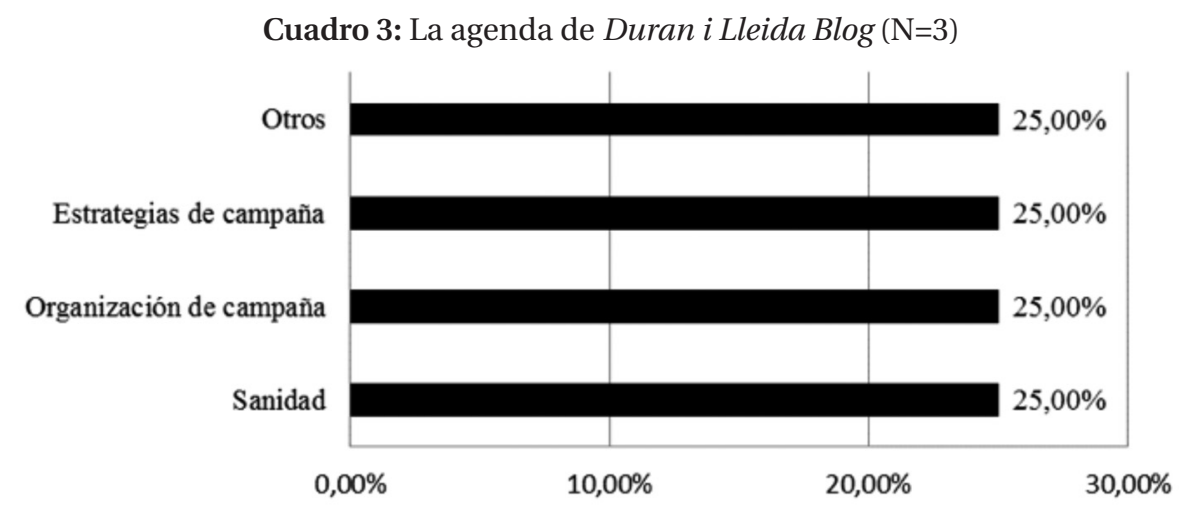

Fuente: Elaboración propia

Como en los casos anteriores, los temas relacionados con la campaña electoral son predominantes en la agenda de Duran i Lleida Blog, sobre todo en lo referente a la organización (25\%) y las estrategias (25\%). El único asunto público sustantivo que se menciona es la sanidad (25\%), aunque conviene moderar también el alcance de dichos resultados a tenor de la escasa composición de la muestra.

La agenda del blog de Joan Josep Nuet, coordinador general de Esquerra Unida i Alternativa (referente de Izquierda Unida en Cataluña y coaligado con Iniciativa per Catalunya Verds) y número 3 de la candidatura de ICV-EUiA al Congreso de los Diputados por Barcelona, también presenta una mayor proporción de temas relacionados con la campaña electoral (51,61\%) que de asuntos públicos (48,39\%). 
Cuadro 4: La agenda de El bloc de Joan Josep Nuet $(\mathrm{N}=14)$

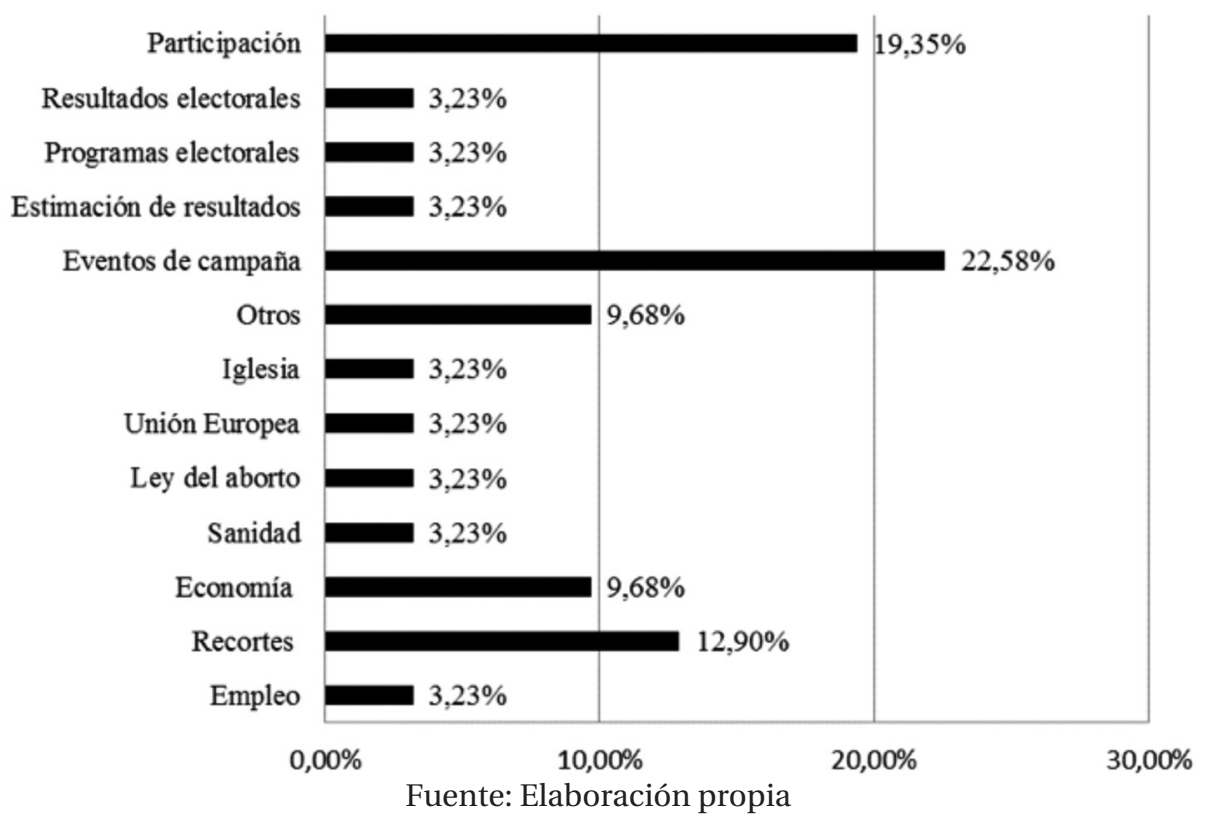

Nuet se ocupa de la estimación de resultados (3,23\%), los programas electorales (3,23\%), los resultados (3,23\%), la participación (19,35\%) y, sobre todo, aunque en menor proporción que Leire Pajín, de los eventos de campaña que protagoniza o en los que participa $(22,58 \%)$.

En cuanto a los temas relacionados con políticas públicas, El bloc de Joan Josep Nuet reproduce parcialmente la agenda tradicional de la esfera ideológica de la izquierda: recortes económicos y sociales (12,9\%), otras cuestiones económicas $(3,23 \%)$, empleo (3,23\%), sanidad (3,23\%), ley del aborto (3,23\%), Unión Europea $(3,23 \%)$ y relaciones con la Iglesia $(3,23 \%)$.

El blog de Iñaki Anasagasti, candidato al Senado por el Partido Nacionalista Vasco en la circunscripción de Vizcaya, es la bitácora política analizada con una mayor presencia de temas no estrictamente políticos, presentes en 34 de las 72 publicaciones (47\%) que realizó durante la campaña electoral. Dado que el objetivo de la presente investigación es analizar la agenda temática de contenido político, hemos optado por excluir dichos artículos de la muestra.

El candidato del PNV mantiene la prevalencia de los aspectos relacionados con la campaña electoral $(52,63 \%)$ sobre los vinculados con políticas públicas $(44,74 \%)$. 
Cuadro 5: La agenda del blog Iñaki Anasagasti (N=38)

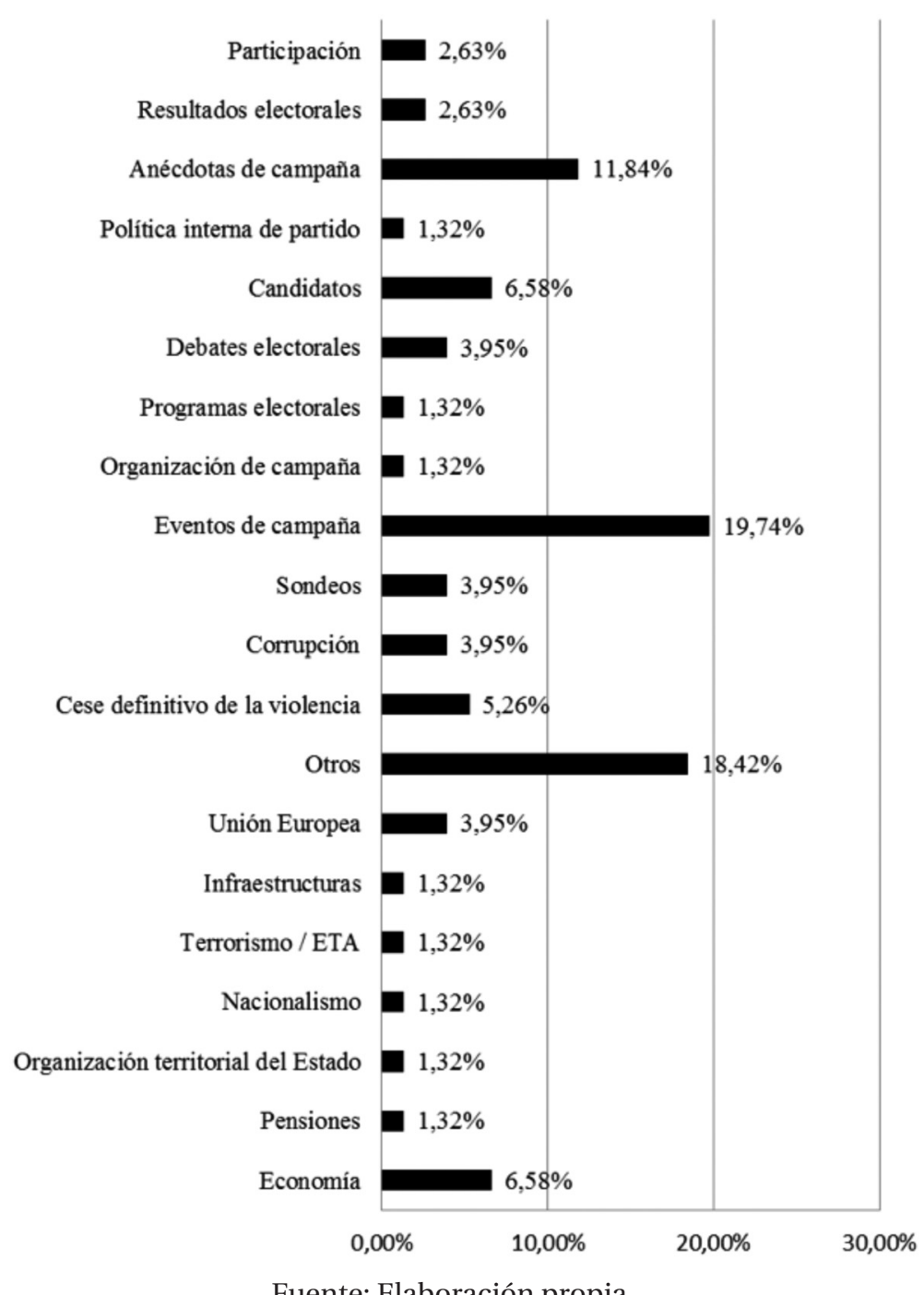

Fuente: Elaboración propia

Anasagasti, como Pajín y Nuet, escribe sobre todo de los eventos de la campaña en los que participa (19,74\%), pero también se ocupa de anécdotas ocurridas durante dichos actos $(11,84 \%)$ y de la personalidad y cualidades de otros candidatos (6,58\%), tanto de su formación como de otros partidos. Además, presta atención a otras cuestiones relacionadas con la 
campaña, como los sondeos (3,95\%), los debates electorales (3,95\%), la estimación de resultados (2,63\%), la participación $(2,63 \%)$, la organización de la campaña $(1,32 \%)$, los programas $(1,32 \%)$ y la política interna de partido $(1,32 \%)$.

En cuanto a los asuntos relacionados con políticas públicas, el candidato se ocupa de diversas cuestiones económicas (6,58\%), las pensiones (1,32\%), la Unión Europea (3,95\%) y otros temas (18,42\%). También lo hace de aspectos propios de la agenda política nacionalista, en general, como la organización territorial del Estado (1,32\%) y las infraestructuras (1,32\%), y de la agenda nacionalista vasca en particular, como es el caso del cese definitivo de la violencia $(5,26 \%)$ y del terrorismo $(1,32 \%)$, que, sin embargo, no estuvieron especialmente presentes en la agenda de la campaña a tenor de la coyuntura fuertemente económica.

Carlos Martínez Gorriarán, responsable de Acción Política de UPyD y número 2 de la candidatura de la formación al Congreso de los Diputados por Madrid, es el político analizado que menos alude en su blog a aspectos relacionados con la campaña electoral y que más lo hace a asuntos públicos. Así lo refleja el hecho de que sólo dedique el 16,67\% de los artículos a una cuestión estrictamente electoral, como es la personalidad y las cualidades de los candidatos.

Cuadro 6: La agenda de El Blog de Carlos Martínez Gorriarán (N=3)

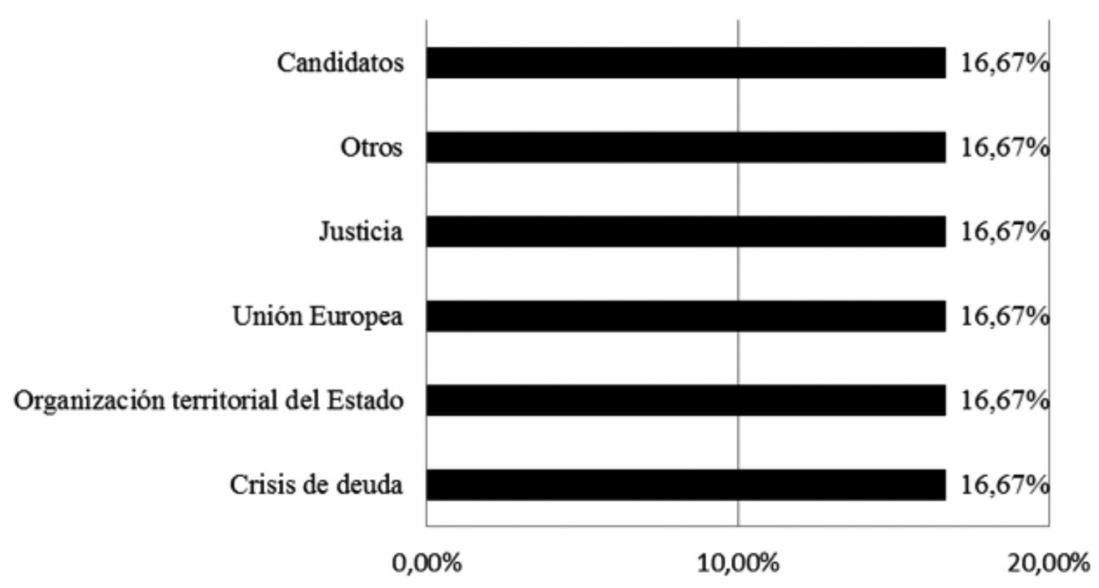

Fuente: Elaboración propia

La agenda temática de Gorriarán se reparte en proporciones iguales entre la crisis de la deuda y la Unión Europea, así como entre dos aspectos que forman parte del núcleo discursivo de su formación: la organización territorial del Estado y el funcionamiento de la justicia. Con todo, y como en los casos de Cospedal y Duran i Lleida, conviene moderar el alcance de dichos datos al estar referidos a una muestra de sólo tres publicaciones. 


\subsection{Los blogs periodísticos}

La agenda de Escolar.net se ocupa generosamente de los temas específicamente relacionados con la campaña electoral como acontecimiento político. Escolar se hace eco tanto de los aspectos estratégicos (como los sondeos, la estimación de resultados y las estrategias electorales) como de las cuestiones más simbólicas de la contienda (eventos, debates electorales). Asimismo, esta bitácora presta abundante atención a los programas electorales con los que los partidos políticos se presentaban a los comicios $(11,54 \%)$.

Además, la agenda de este periodista parece recoger las prioridades temáticas de uno de los dos principales partidos políticos españoles: el Partido Socialista Obrero Español (PSOE), cuya agenda temática durante la campaña estuvo esencialmente basada en cuestiones de carácter económico, como resultado de la fuerte coyuntura de crisis, y, sobre todo, en temas relacionados con la supervivencia del Estado de Bienestar (Valera y López, 2014), tal como reflejan también los resultados relativos a los blogs de Cospedal y Pajín. Así, tanto el desempleo como la crisis concitan el 9,62\% de la atención, mientras que el 7,69\% de las publicaciones se ocupan de otros aspectos económicos. 
Cuadro 7: La agenda del blog Escolar.net, de Ignacio Escolar (N=19)

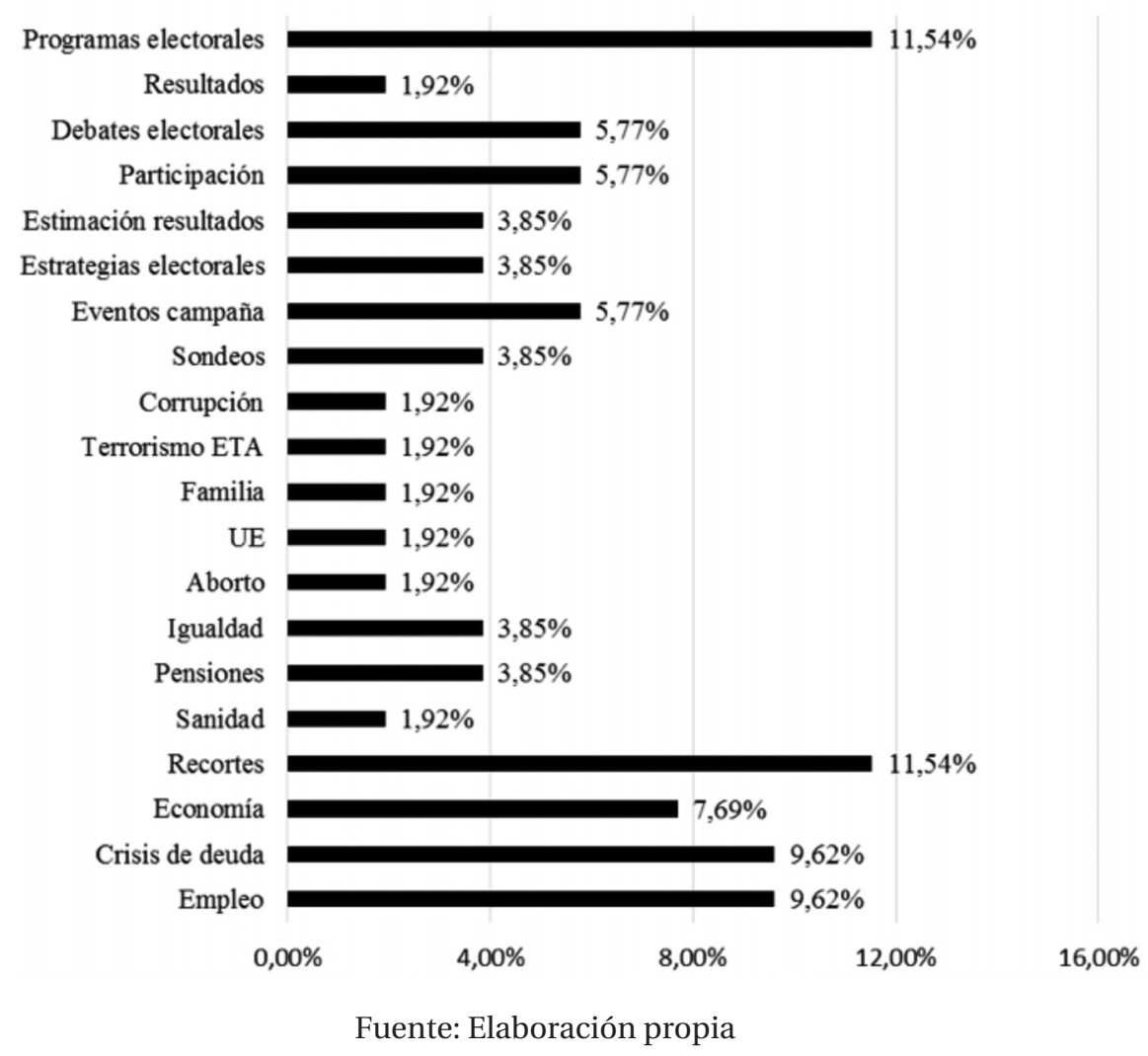

Por su parte, los temas sociales presentan una frecuencia conjunta de aparición del 23,08\% si sumamos las cuestiones relativas a los recortes sociales, la sanidad pública, el sistema de pensiones, las políticas de igualdad y la ley del aborto. Este sesgo social de la agenda de Escolar, así como su proximidad con la agenda del PSOE, resulta evidente en tanto que el tema más destacado son los recortes sociales, que están presentes en el 11,54\% de los artículos. Conviene recordar, en este punto, que la campaña electoral de los socialistas giró en torno a la supervivencia del Estado de Bienestar y las políticas sociales, lo que incluyó un énfasis notable en los recortes que acometería un hipotético ejecutivo popular.

El Blog de Federico presenta una agenda que concede una atención equivalente al nacionalismo, la ilegalización de la izquierda abertzale, la corrupción y la política interna de partido, además de especular en torno a la estimación de los resultados y dedicar atención a los porcentajes de votos y escaños finalmente obtenidos por las fuerzas políticas. 
Cuadro 8: La agenda de El Blog de Federico, de Jiménez Losantos (N=2)

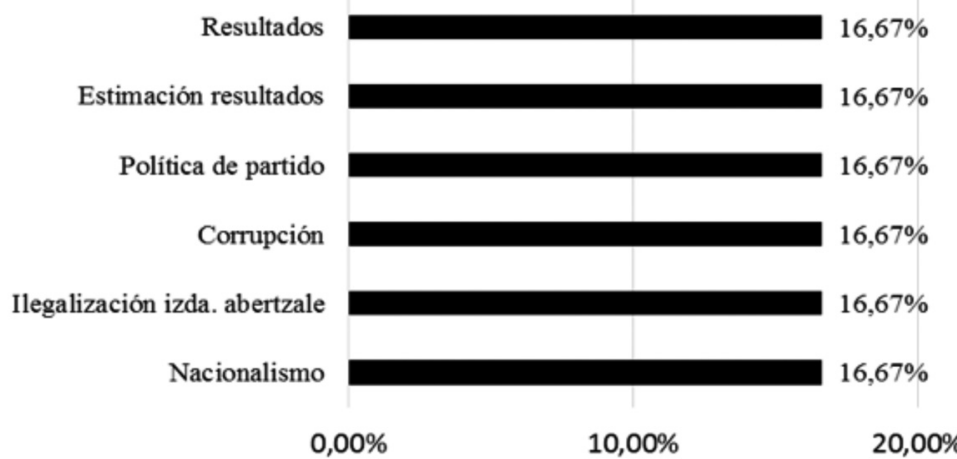

Fuente: Elaboración propia

En los dos primeros casos, la agenda de Jiménez Losantos refleja una obsesión clásica de la esfera ideológica conservadora: el nacionalismo periférico y la presencia institucional de la izquierda abertzale, pese a que ninguna de estas cuestiones tuvieron ninguna centralidad en la campaña electoral a tenor de la grave crisis económica. En este sentido, por lo tanto, la agenda de El Blog de Federico no parece sensible a las cuestiones más destacadas por los principales partidos políticos españoles, que basaron sus estrategias electorales en cuestiones estrictamente económicas (en el caso popular), y en una combinación de éstas con los temas sociales (en el caso socialista). Con todo, conviene moderar el alcance de estos resultados a tenor de la limitación de la muestra, ya que este periodista sólo publicó dos entradas durante el marco temporal estudiado. 
Cuadro 9: La agenda de El Mundo por dentro y por fuera, de Arcadi Espada (N=12)

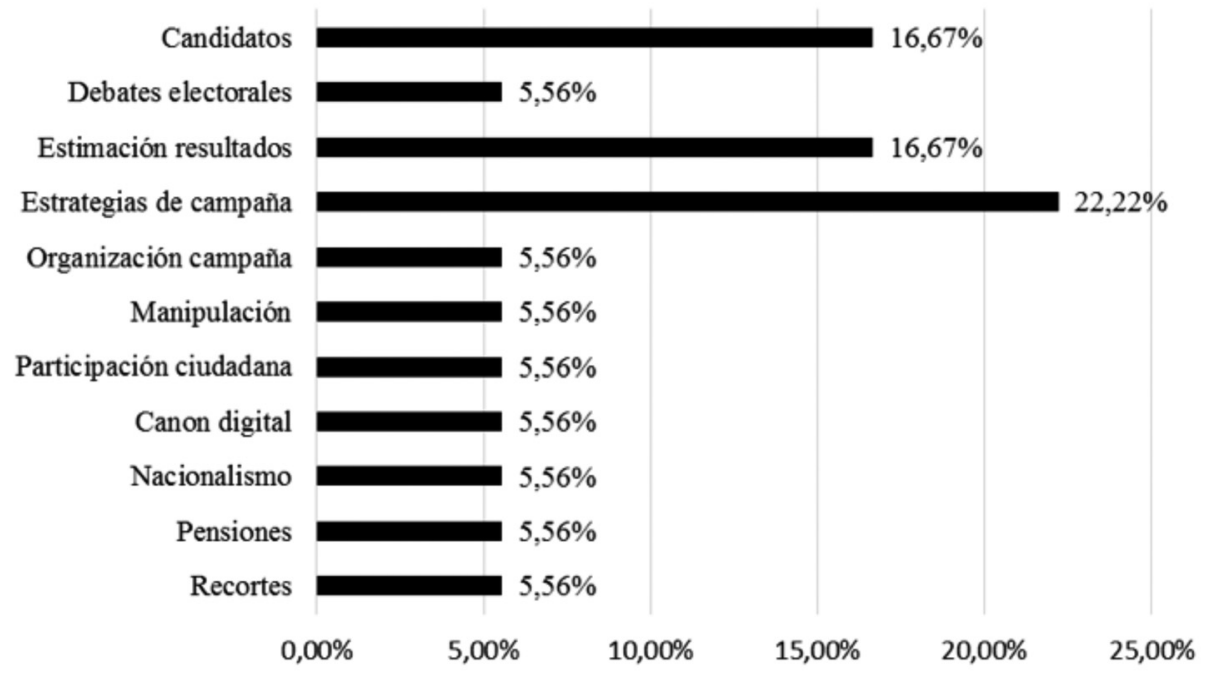

Fuente: Elaboración propia

El blog El Mundo por dentro y por fuera, de Arcadi Espada, presta escasa atención a cuestiones específicas de política pública, y en lugar de ello se centra en cuestiones relacionadas con la campaña electoral en su conjunto, en donde aporta su opinión sobre determinados actos de campaña, el carácter y personalidad de los candidatos (en particular, Mariano Rajoy y Alfredo Pérez Rubalcaba) y, sobre todo, se centra en aventurar cuáles pueden ser los resultados de las elecciones, y sus consecuencias.

Finalmente, el blog Punto de vista, de Jesús Ceberio, combina igualmente su interés por la estimación de los posibles resultados de la campaña con una dispersión temática mayor, en la que destacan dos focos de atención principales. Por un lado, lo relacionado con la economía y la gestión de la crisis económica; por otro, lo relativo al terrorismo de ETA, vinculado a su vez con el nacionalismo vasco.

Llama poderosamente la atención, en este sentido, que la agenda temática de Jesús Ceberio podría considerarse muy similar a la de los medios o blogs conservadores, o incluso a la campaña del propio PP, muy centrada en la crítica de la gestión socialista de la crisis. Sin embargo, en este caso la convergencia temática no supone también una coincidencia en el enfoque argumentativo, puesto que Ceberio se centra en dichos temas con un planteamiento claramente cercano a las posiciones del PSOE. 
Cuadro 10: La agenda del blog Punto de vista, de Jesús Ceberio (N=18)

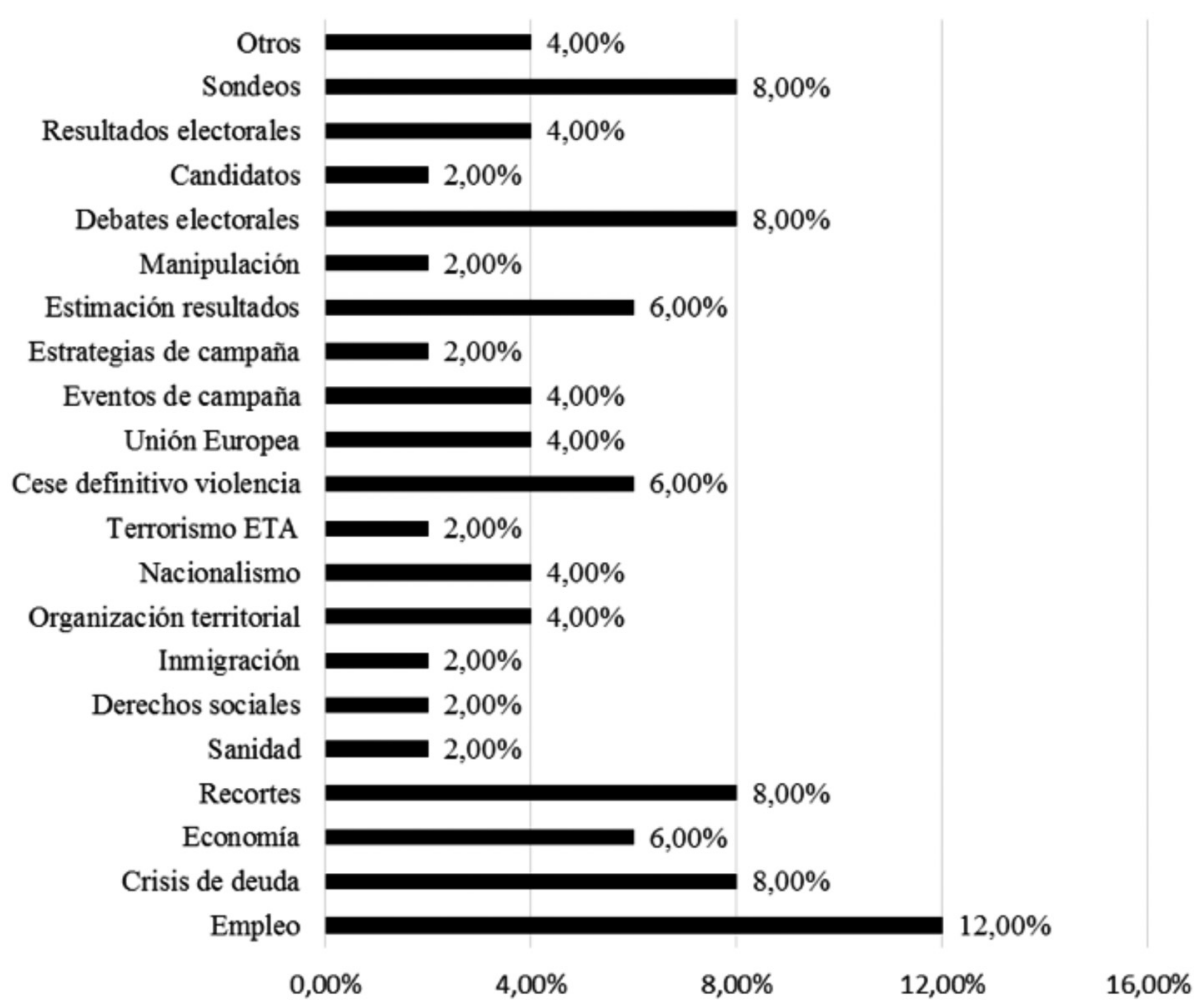

Fuente: Elaboración propia

En lo relativo a la economía, Ceberio desplaza la crisis económica del marco del Estado-nación y la traslada al espacio competencial de la Unión Europea, en una operación discursiva idéntica a la que despliega el PSOE durante la campaña electoral a través del marco "influir en Europa", que permite a los socialistas soslayar su propia responsabilidad en la gestión de la crisis y situarla en el espacio institucional de la Unión Europea como único foro capaz de resolverla (Valera Ordaz, 2014b).

Además, Ceberio presta también atención a cuestiones de carácter social, como los recortes (8\%), la sanidad (2\%) y los derechos sociales $(2 \%)$, lo que sugiere cierta proximidad con la estrategia socialista de combinar las preocupaciones económicas con la supervivencia del Estado de Bienestar.

En lo que se refiere al terrorismo de ETA, la aportación de Ceberio va dirigida a reivindicar el mérito del Partido Socialista, y en concreto de los dirigentes del PSE, por el fin de la violencia terrorista de ETA. De hecho, Ceberio llega a lamentarse 
por la evidencia de que dicho éxito, que en otras épocas, por sí mismo, habría garantizado la reelección del gobierno que lo alcanzara, ahora quede totalmente en segundo plano como consecuencia de la crisis económica.

\subsection{Los blogs ciudadanos}

El blog Punts de vista muestra una distribución temática canónica, desde el punto de vista de las preocupaciones clásicas de la izquierda, así como de la agenda de los partidos de izquierda en esta campaña: la mayoría de sus artículos se centran en la defensa de los derechos sociales (3,85\%) y la preocupación por los recortes que puedan aplicarse después del 20N (26,92\%), así como los que ya se han aplicado con el gobierno de Rodríguez Zapatero. Mención aparte merece la abundancia de alusiones a la defensa de la sanidad pública, presentes en el 19,23\% de los artículos analizados. Además, las cuestiones relacionadas con la campaña electoral (resultados, anécdotas, debates, estimación de resultados, etc.) no resultan especialmente centrales, por cuanto su aparición conjunta se sitúa en el 26,95\%.

Cuadro 11: La agenda del blog Punts de vista (N=9)

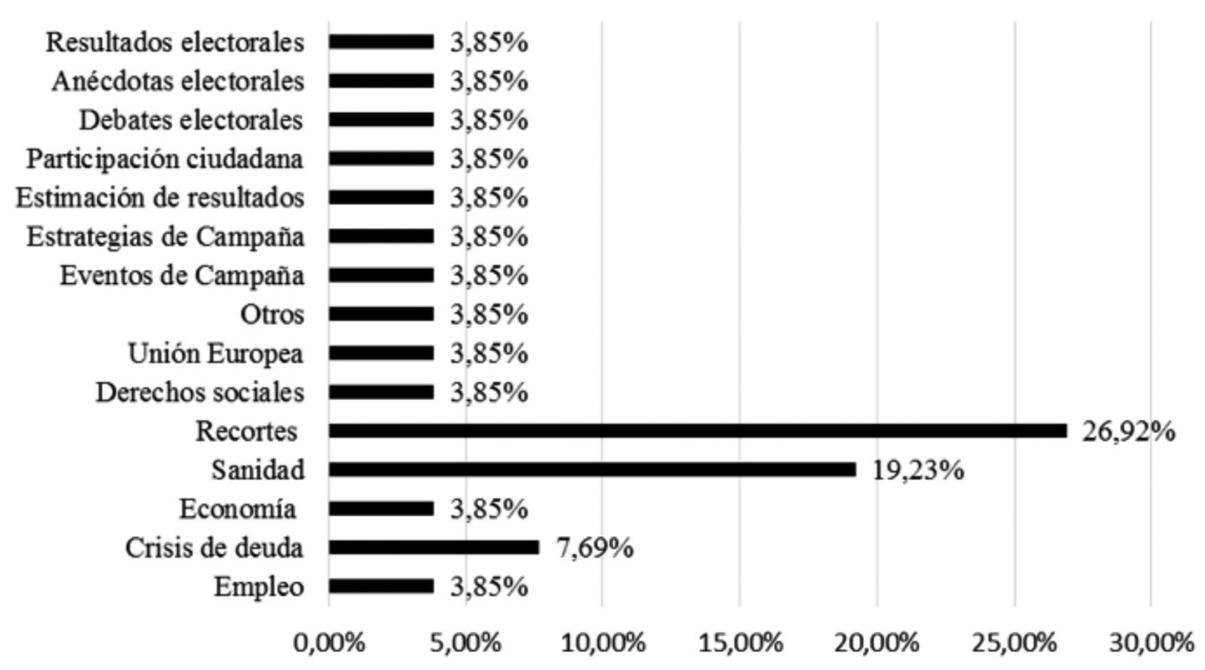

Fuente: Elaboración propia

En lo que se refiere al blog Batiburrillo, su distribución temática es similar a la de otros blogs conservadores que hemos analizado, como el blog de Arcadi Espada, con el que coincide en su preocupación por el análisis de los actos de campaña electoral (prestando atención a los candidatos, las anécdotas de la campaña y las estrategias) y la evaluación de los posibles resultados de las elecciones (11,76\%). También destaca, en consonancia con la mayoría de los blogs, su énfasis, en este 
caso relativamente significativo, en los temas económicos. En efecto, el empleo y las pensiones obtienen cada uno una frecuencia de aparición de 5,88\%, mientras que la economía en sentido amplio concentra el protagonismo de un 17,65\% de los artículos.

Cuadro 12: La agenda del blog Batiburrillo (N=7)

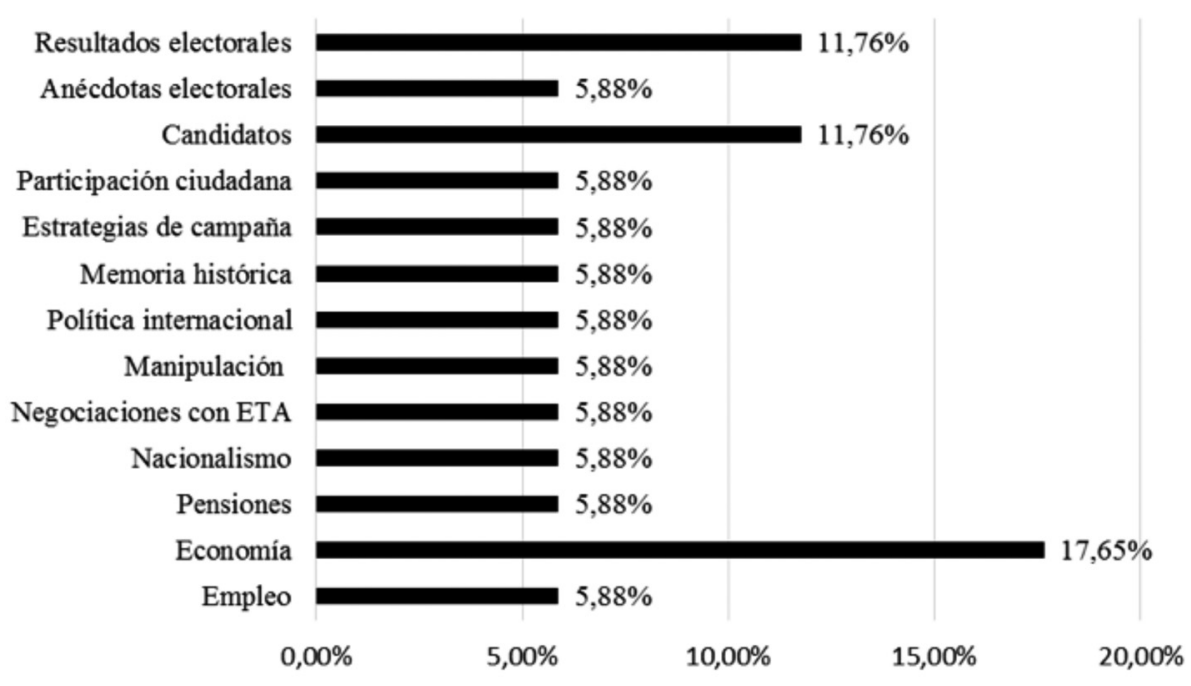

Fuente: Elaboración propia 


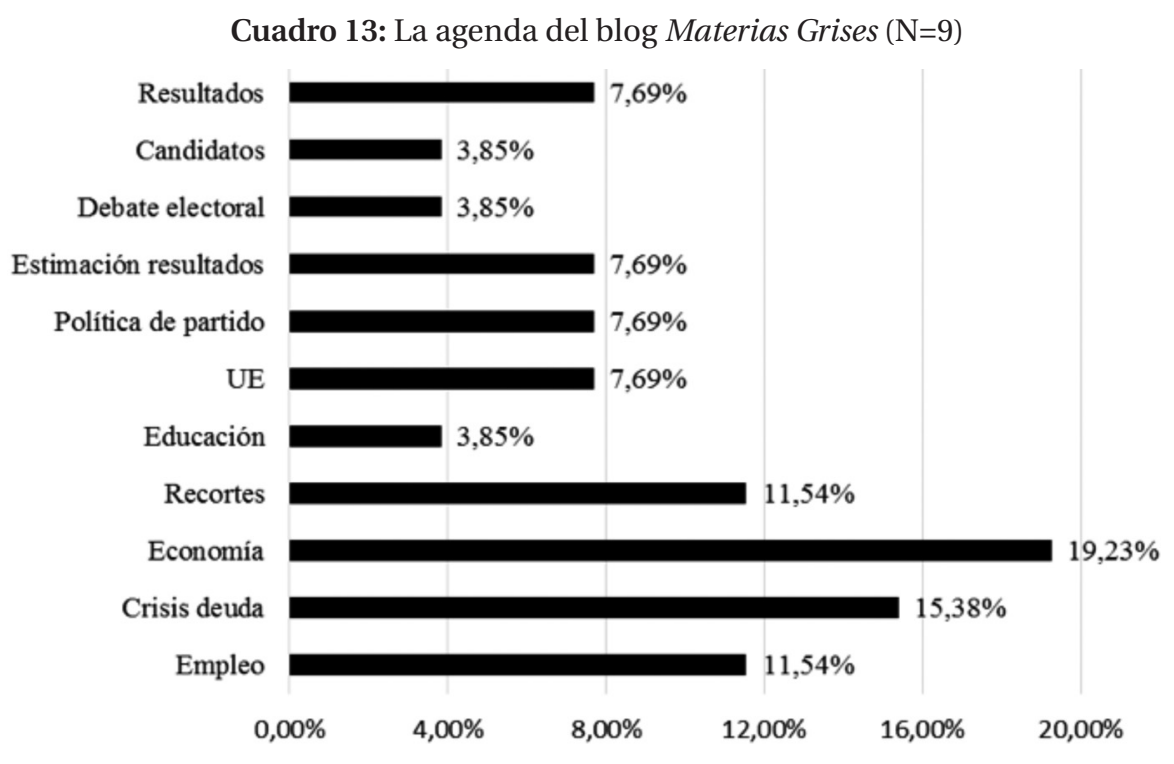

Fuente: Elaboración propia

Por su parte, la agenda temática de Materias Grises está sin duda centrada en cuestiones de carácter económico, como indica la importancia concedida a cuestiones como el empleo (11,54\%), la crisis de deuda $(15,38 \%)$ y la economía en sentido amplio (19,23\%). También aparecen, no obstante, cuestiones sociales, como la educación (3,85\%) y la especulación en torno a los recortes $(11,54 \%)$, pero indudablemente se trata de una agenda principalmente basada en la coyuntura económica. Asimismo, este ciudadano presta atención a cuestiones más íntimamente relacionadas con la campaña electoral, como la estimación de resultados (7,69\%), el debate electoral (3,85\%), los candidatos (3,85\%) o los resultados de los comicios $(7,69 \%)$.

Finalmente, el blog Desde el Exilio presenta una agenda temática que también prioriza las cuestiones económicas, especialmente la crisis de deuda, que es, sin duda, el tema más enfatizado durante el marco temporal estudiado. También revisten cierta importancia los recortes económicos y sociales, y, en menor medida, la sanidad, la manipulación informativa y la Unión Europa, entre otros. Asimismo, las cuestiones estrictamente electorales también son tratadas por este ciudadano. En concreto, las estrategias desplegadas por los actores políticos, los debates electorales y la estimación de los resultados de los comicios. 


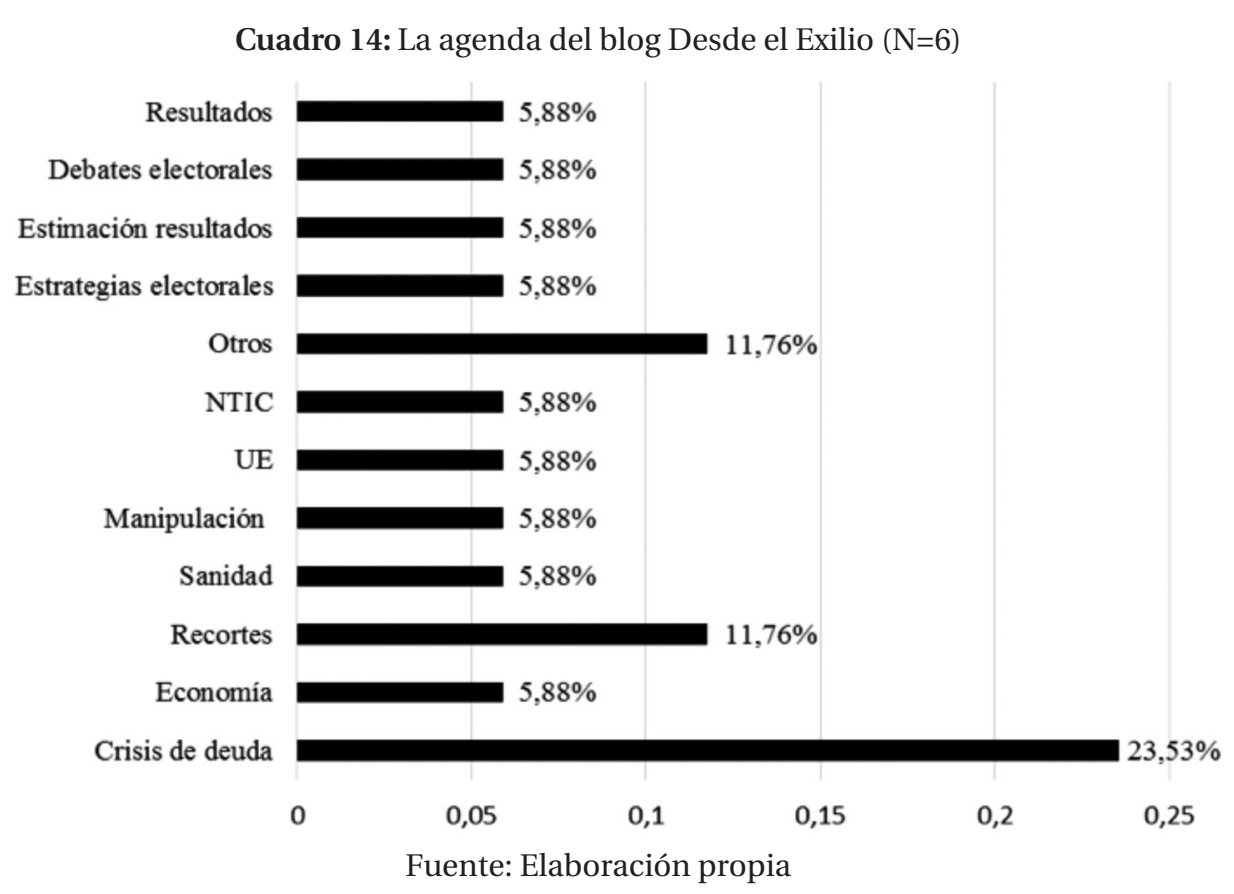

\section{Conclusiones}

Los resultados han puesto de manifiesto que los asuntos estrictamente relacionados con la propia campaña electoral prevalecen de forma clara en las agendas de los blogs de cinco de los seis candidatos políticos analizados (Cospedal, Pajín, Nuet, Duran y Anasagasti). Sólo el candidato de UPyD, Carlos Martínez Gorriarán, presenta una agenda temática más orientada hacia la discusión de políticas públicas, en detrimento del propio devenir de la campaña electoral. En general, sin embargo, el uso que los candidatos hacen de estas herramientas de comunicación consiste principalmente en la visualización y publicitación de sus actos de campaña, junto con otras muchas cuestiones electorales (como el llamamiento a la participación, información sobre sondeos, estimación de resultados y debates electorales). En este sentido, los resultados de nuestra investigación refrendan el acuerdo general de la academia en torno al uso eminentemente informativo-propagandístico de las herramientas de comunicación digital por parte de partidos y candidatos (Dader, 2009). En efecto, los resultados hallados en torno al uso de los blogs por parte de candidatos políticos españoles coinciden con la función eminentemente informativa-persuasiva de las webs partidistas señalada por una pléyade de estudios internacionales y nacionales (Dader y Díaz, 2007; Owen y Davis, 2008; Schweitzer, 2009; Campos, 2011; Dader et al., 2011). 
Lejos de configurarse en espacios de reflexión y debate sustantivo sobre políticas públicas, las bitácoras de los candidatos funcionan esencialmente como instrumentos de marketing político a través de los cuales publicitar el desarrollo de la campaña.

No obstante, en lo referido a los temas relacionados con políticas públicas, la composición de las agendas de los candidatos exhibe, como era de esperar, una estrecha similitud tanto con la agenda general de las esferas ideológicas en las que se inscriben como con la agenda particular de los partidos a los que representan. Así, por ejemplo, la agenda de Cospedal se ocupa principalmente de cuestiones económicas, mientras que la de Pajín revela un doble sesgo económico y social (recortes, sanidad, ley del aborto), en perfecto alineamiento con las agendas temáticas de PP y PSOE durante la campaña de 2011 (Valera y López, 2014; Valera, 2015). En otras palabras, los candidatos, además de publicitar todo tipo de cuestiones relacionadas con el devenir de la campaña, reproducen y difunden las prioridades temáticas de los partidos a los que representan.

En comparación con estos espacios a cargo de candidatos políticos, los blogs periodísticos presentan agendas temáticas menos orientadas hacia la contienda electoral, pues en estas los temas de campaña sólo están presentes aproximadamente en un tercio de los artículos publicados en tres de los casos analizados (Escolar, Jiménez Losantos y Ceberio). Es decir, en general, los periodistas dedican más atención al debate de distintos ámbitos de política pública que los propios candidatos, en detrimento del seguimiento minucioso de las cuestiones electorales. El Mundo por dentro y por fuera, sin embargo, constituye una excepción, pues en él Espada sí realiza un seguimiento más exhaustivo de toda clase de aspectos relacionados con la campaña (estrategias electorales, estimación de resultados). Con un enfoque mucho más crítico y 'excéntrico', en el sentido de su posicionamiento al respecto de la campaña en sí, que el de los candidatos, claro está. Así, los resultados sugieren que, en general, las bitácoras periodísticas tienden a acoger un debate esencialmente sustantivo de los asuntos de interés general durante la campaña.

En cuanto a la convergencia temática de los blogs periodísticos con las agendas de partidos y candidatos, los resultados arrojan ciertas similitudes. En el caso de los blogs progresistas (Escolar y Ceberio), ambos se hacen eco de las prioridades programáticas del PSOE y dedican abundante atención a las cuestiones económicas (empleo, crisis de deuda, etc.), pero insistiendo en la necesidad de mantener las políticas sociales (sanidad, educación, derechos sociales, etc.) y en el escaso margen de maniobra que la Unión Europea imponía a los gobiernos nacionales. Por su parte, los blogs de sesgo más conservador exhiben una mayor independencia respecto de la agenda popular. Así, tanto Jiménez Losantos como Espada prestan atención a cuestiones como el nacionalismo o la ilegalización de la izquierda abertzale. Es decir, tratan temas ajenos a la agenda eminentemente económica del PP durante la campaña, pero que a su vez constituyen preocupaciones históricas de la derecha española.

En resumen, el debate público acogido por los blogs periodísticos analizados sí supone un cierto ensanchamiento de la esfera pública, en tanto en cuanto los temas preponderantes constituyen en su mayoría cuestiones de interés público. 
Frente a la tendencia de los medios de comunicación tradicionales a presentar las campañas como horseraces, es decir, a enfatizar los aspectos relacionados con las probabilidades de victoria o fracaso de los actores políticos (Nimmo, 1996; Rospir, 1996; Mazzoleni, 1996; Swanson y Mancini, 1996), los blogs a cargo de periodistas parecen erigirse en un refugio para la discusión de contenidos programáticos y el debate de políticas públicas, a pesar de que este debate tienda a distribuirse en esferas ideológicas alineadas temáticamente con los partidos contendientes.

Finalmente, los blogs a cargo de ciudadanos anónimos también se ocupan en menor medida de los temas relacionados con el devenir de la propia campaña, en comparación con las bitácoras periodísticas, y, sobre todo, con los blogs de los candidatos políticos. Es decir, tanto periodistas como ciudadanos acogen en sus blogs debates significativamente más sustantivos que los candidatos. Lo que nos permite atribuir a la blogosfera política española (a la compuesta por periodistas y ciudadanos) una función de enriquecimiento de la esfera pública, por cuanto acoge un debate esencialmente sustantivo sobre los asuntos de interés general.

En términos de convergencia temática con las agendas partidistas, los blogs ciudadanos presentan resultados ligeramente variables. Algunos espacios (como es el caso de Punts de vista) sí que exhiben agendas temáticas canónicas con respecto a su esfera ideológica y formación política de referencia (Izquierda Unida). Pero, en general, estos alineamientos temáticos con respecto a las agendas partidistas son moderados. Así, Materias Grises exhibe cierta proximidad con la agenda socialista, por cuanto presenta una agenda económica con ciertos matices sociales. Por su parte, tanto Desde el exilio como Batiburrillo reproducen la agenda esencialmente económica popular, pero el segundo también incorpora otras prioridades temáticas clásicas de la derecha (nacionalismo, terrorismo de ETA) que no estuvieron presentes durante la campaña.

En resumen, esta investigación ha puesto de manifiesto que los blogs de candidatos políticos tienden principalmente a convertirse en espacios de visibilización y publicitación de la actividad política durante la campaña. En este sentido, nuestro estudio refrenda los hallazgos anteriores en torno al uso esencialmente propagandístico de los blogs por parte de los candidatos españoles en campaña electoral (Peytibi et al., 2008; Dader, 2009).

Asimismo, refleja que los blogs a cargo de periodistas y ciudadanos se configuran como un foro de debate de las cuestiones de interés general, de forma que contribuyen a fomentar el enriquecimiento del espacio público y la circulación de opiniones e ideas ajenas a los cauces hegemónicos de comunicación, suscribiendo así la percepción positiva de las tecnologías digitales como factor de apertura del modelo vertical de comunicación de masas (Davis, 2009; Farrel et al., 2008; Maratea, 2008).

No obstante, este estudio también revela que esta apertura se produce en un contexto en que los blogs periodísticos y ciudadanos tienden a reproducir las prioridades temáticas y las agendas de los partidos políticos y las esferas ideológicas en las que se inscriben sus autores de forma más o menos explícita. Ello dibuja un escenario complejo, en el que conviene con- 
traponer los riesgos de fragmentación ideológica de la esfera digital a los beneficios derivados del ensanchamiento del espacio público. Futuros estudios deberán analizar mediante apuestas metodológicas más sofisticadas (que incluyan enfoques triangulados) y corpus más amplios hasta qué punto la blogosfera política se configura como un espacio independiente de debate público.

\section{Referencias bibliográficas}

Abold, R. y Heltsche, M. (2006): “Weblogs in Political Campaigns-The Critical Success Factors”. [Paper presented at Blog Talk Reloaded, Vienna, Austria].

Adamic, L. y Glance, N. (2005): “The Political Blogosphere and the 2004 U.S. Election: Divided They Blog”. [Paper presented at the Annual Workshop on the Webblogging Ecosystem].

Albrecht, S.; Lübcke, M.; y Hartig-Perschke, R. (2009): “Under Construction:Weblog Campaigning in the German Bundestag Election 2005”, en Panagopoulos, C. (ed.): Politicking Online: The Transformation of Election Campaign Communications. Nueva Jersey: Rutgers, pp. 179-199.

Anduiza, E.; Cantijoch, M. y Cristancho, C. (2010): “Los ciudadanos y el uso de Internet en la campaña electoral”, en Montero, J.R. y Lago, I. (eds.): Las elecciones generales de 2008. Madrid: CIS, pp. 123-142.

Auty, C. (2005): “UK Elected Representatives and their Weblogs: First Impressions”, Aslib Proceedings, vol. 57, pp. 338-355. Campos-Domínguez, E. (2011): La ciberdemocracia en el Congreso de los Diputados (2004-2008). Madrid: Congreso de los Diputados.

Coleman, S. y Ward, S. (2005): Spinning the Web: Online Campaigning in the 2005 General Election. Londres: Hansard Society.

Dader, J. L. (2009): “Ciberpolítica en los websites de partidos políticos: la experiencia de las elecciones de 2008 en España ante las tendencias transnacionales”, Revista de Sociología e Política v. 17, n. 34, pp.45-62.

Dader, J. L. y Díaz Ayuso, I. (2007): “Las webs de partidos españoles 2004-2005: Una investigación preliminar y de comparación europea, con una propuesta metodológica”. [Actas del II Congreso de Comunicación Política. Madrid: Universidad Complutense de Madrid, 8 y 9 de marzo].

Dader, J. L.; Campos, E.; Vizcaíno, R. y Chen, L. (2011): “Las web de los partidos durante la campaña para las Elecciones Generales de 2008: Pautas de cibermarketing con pocos signos de ciberdemocracia”, en Sampedro, V. (coord.): Cibercampaña. Cauces y diques para la participación. Las Elecciones Generales de 2008 y su proyección tecnopolítica. Madrid: UCM, pp. 145-200.

Davis, R. (2009): Typing Politics: The Role of Blogs in American Politics. Nueva York: Oxford University Press.

Drezner, D. y Farrell, H. (2008): “The Power and Politics of Blogs”, Public Choice, n. 134. pp. 15-30. 
Farrell, H.; Lawrence, E. y Sides, J. (2008): “Self-Segregation or Deliberation?: Blog Readership, Participation and Polarization in American Politics". Paper presented at the Annual Meeting of the Midwest Political Science Association, Chicago, 3-6 Abril.

Fouetillou, G. (2011): “De 2007 à 2011, l'évolution de la blogosphère politique”. http://politicosphere.blog.lemonde.fr/2011/ 07/04/de-2007-a-2011-levolution-de-la-blogosphere-politique/ [Consultado el 14/04/2015]

Gibson, R. y Römmele, A. (2007): “Political Communication”, en Caramani, D. (ed): Comparative Politics. Oxford: Oxford University Press.

Gillin, P. (2007): Los nuevos influyentes. Madrid: LID.

Gillmor, D. (2004): We the Media: Grassroots Journalism by the People, for the People. Sebastopol: O'Reilly.

Hallin, D. y Mancini, P. (2004): Sistemas mediáticos comparados: Tres modelos de relación entre los medios de comunicación y la política. Barcelona: Hacer.

Hargittai, E.; Gallo, J. y Kane, M. (2008): “Cross-Ideological Discussions among conservative and liberal bloggers”, Public Choice, n. 134, pp. 67-86.

Hennessy, C.L. y Martin, P.S. (2006): "Blogs, the Mainstream Media and the War in Irak”. [Paper presented at the Annual Meeting of the American Political Science Association, Philadelphia, 31 de Agosto-3 de Septiembre].

Himmelsbach, S. (2005): “Blog: the New Public Forum”, en Latour, B. y Weibel, P. (ed.): Making Things Public: Atmospheres of Democracy. Cambridge: MIT Press, pp. 916-921.

Jackson, N. (2006): "Dipping Their Big Toe into the Blogosphere: The Use of Weblogs by the Political Parties in the 2005 General Election”, Aslib Proceedings, vol. 58, pp. 292-303.

Jenkins, H. (2006): Convergence Culture: La cultura de la convergencia de los medios de comunicación. Barcelona: Paidós.

Kelly, J. (2008). "Pride of Place: Mainstream Media and the Networked Public Sphere". Media Re: Public. Side of Papers. Berkman Center for Internet and Society at Harvard University.https://cyber.law.harvard.edu/sites/cyber.law.harvard.edu/ files/Pride\%20of\%20Place_MR.pdf [Consultado el 25/03/2015]

Klastrupp, L. y Pedersen, P. (2007): "Blogging for Election. The Use and Function of Blogs as Communication Tool in a Danish Parliamentary Election Campaign”, en Consalvo, M. y Haythornthwaite, C. (eds): Internet research Annual 2005: Selected Papers from the Association of Internet Researcher Conference 2005. Nueva York: Peter Lang, pp. 27-40.

Lévy, P. (2004): Ciberdemocracia. Ensayo sobre Filosofía Política. Barcelona: UOC.

Lilleker, D.G. y Jackson, N.A. (2011): “France 2007: tentative interactivity”, en Lilleker, D.G. y Jackson, N.A. (eds.): Political Campaigning, Elections and the Internet: Comparing the US, UK, France and Germany. Milton Park, Abingdon, Oxon, New York: Routledge, pp. 55-75.

López García, G. (2006): “Comunicación en red y mutaciones de la esfera pública”, Zer, n. 20, pp. 231-249. 
López García, G. y Lara, T. (2009): “Weblogs y procesos electorales: la blogosfera política española ante las elecciones generales de 2008”, Quaderns del CAC, n. 33, pp. 43-51.

López García, G. y Clemente Sastriques, C. (2010): "Posicionamientos ideológicos y agenda mediática. Un análisis de la blogosfera española en las últimas elecciones generales", Miguel Hernández Communication Journal n. 1, pp. 255-285.

López García, G.; Lara, T. y Sánchez Duarte, J. M. (2011): “Los weblogs como mecanismos de reafirmación ideológica: la blogosfera española ante las Elecciones Generales de 2008", en Sampedro, V. (ed.): Cibercampaña. Cauces y diques para la participación. Las Elecciones Generales de 2008 y su proyección tecnopolítica. Madrid: Editorial Complutense. pp. 201-236.

López García, G.; Campos Domínguez, E. y Valera Ordaz, L. (2013): “Agenda temática, estrategias discursivas y deliberación en la campaña electoral de 2011: Análisis de los blogs de Jesús Ceberio (El País) y Arcadi Espada (El Mundo)”, Zer, vol. 18, n. 34, pp. 49-72.

Maratea, R. (2008): “The e-Rise and Fall of Social Problems: The Blogosphere as a Public Arena”, Social Problems, vol. 55, n. 1. pp. 139-160.

Mazzoleni, G. (1996): "Patterns and Effects of Recent Changes in Electoral Campaigning in Italy", en Swanson, D. y Mancini, P. (eds): Politics, Media and Modern Democracy: An International Study of Innovations in Electoral Campaigning and Their Consequences. Westport: Praege, pp. 193-206.

- (2010). La comunicación política. Madrid: Alianza Editorial.

Nimmo, D. (1996): “Politics, Media and Modern Democracy: The United States”, en Swanson, D. y Mancini, P. (eds): Politics, Media and Modern Democracy: An International Study of Innovations in Electoral Campaigning and Their Consequences. Westport: Praege, pp. 29-48.

Ott, R. (2006): “Weblogs als Medium Politischer Kommunikation im Bundestagswahlkampf 2005”, en Holtz-Bacha, C. (ed.): Die Massenmedien im Wahlkampf: Die Bundestagswahl 2005. Wiesbaden: Verlag für Sozialwissenschaften, pp. 213-233.

Owen, D. y Davis, R. (2008): “United Stated: Internet and Elections”, en Ward, S.; Owen, D.; Davis, R. y Taras, D. (ed.) (2008): Making a Difference: A Comparative View of the Role of the Internet in Election Politics. Lanham: Lexington Books, pp. 93112.

Peytibi, X.; Rodríguez, J.A. y Gutiérrez-Rubí, A. (2008): “La experiencia de las elecciones generales del 2008”, Revista de Internet, Derecho y Política, n.7, pp. 26-37.

Rheingold, H. (2002): Multitudes inteligentes: la próxima revolución social. Barcelona: Gedisa.

Rospir, J. I. (1996): “Political Communication and Electoral Campaigns in the Young Spanish Democracy”, en Swanson, D. y Mancini, P. (eds): Politics, Media and Modern Democracy: An International Study of Innovations in Electoral Campaigning and Their Consequences. Westport: Praege, pp. 155-169.

Sampedro, V. (2000): Opinión pública y democracia deliberativa: medios, sondeos y urnas. Madrid: Istmo. 
Sampedro, V. y López García, G. (2005): “Deliberación celérica desde la periferia”, en Sampedro, V. (ed.) (2005): 13-M: Multitudes Online. Madrid: Libros de La Catarata, pp. 119-158.

Schweitzer, E. (2009): "Innovation or Normalization in E-Campaigning?: A Longitudinal Analysis of German Party Web Sites in the 2002 and 2005 National Elections". Paper prepared for presentation at the 67th Annual Conference of the Midwest Political Science Association, April 2-5, 2009, Chicago, IL, USA.

Stanyer, J. (2006). "Online Campaign Communication and the Phenomenon of Blogging. An Analysis of Web Logs during the 2005 British General Election Campaign”, Aslib Proceedings, n. 58, pp. 404-415.

Swanson, D. y Mancini, P. (1996): "Patterns of Modern Electoral Campaigning and Their Consequences", en Swanson, D. y Mancini, P. (eds): Politics, Media and Modern Democracy: An International Study of Innovations in Electoral Campaigning and Their Consequences. Westport: Praege.

Sunstein, C. (2001): República.com: Internet, democracia y libertad. Barcelona: Paidós.

Trippi, J. (2008). The Revolution will not be televised. Democracy, the Internet, and the Overthrow of Everything. Nueva York: Harper Collins.

Valera Ordaz, L. (2012): "Blogs ciudadanos en las Elecciones españolas de 2008: Asimilación de la agenda y reproducción de la lógica partidista", Ambitos, n. 21, pp. 207-229.

- (2014a): “El debate público en la blogosfera política española durante la campaña electoral de 2011: ¿ Hacia un espacio público enriquecido o fragmentado?”, Trípodos, n. 34, pp. 153-170.

- (2014b): Agenda building y frame promotion en la campaña electoral 2011: la circulación del discurso entre partidos, medios y ciudadanos. Tesis doctoral, Universidad de Valencia.

- (2015): “Building the news media agenda: how Spanish political parties' influenced newspapers' and blogs' agendas during the Electoral Campaign 2011", Communication \& Society, vol. 28, n. 3, pp. 115-135.

- y López García, G. (2014): "Agenda and frames in the websites of the People’s Party (PP) and the Spanish Socialist Workers' Party (PSOE) in the 2011 cyber campaign”, Revista Latina de Comunicación Social, n. 69, pp. 41-66.

\section{Anexo. Categorías del análisis de contenido}

1) Empleo/Desempleo

2) Impuestos

3) Recortes económicos y sociales

4) Crisis de deuda

5) Vivienda

6) Economía (otras cuestiones) 
7) Educación

8) Sanidad

9) Seguridad ciudadana

10) Familia

11) Inmigración

12) Pensiones

13) Organización territorial del Estado

14) Nacionalismo

15) Terrorismo / ETA

16) Terrorismo / Islamismo

17) Negociaciones con ETA

18) Ilegalización de la izquierda abertzale

19) $15 \mathrm{M}$

20) Sondeos

21) Coaliciones de partidos

22) Eventos de campaña

23) Organización de campaña

24) Estrategias de campaña

25) Estimación de resultados

26) Programas electorales

27) Participación vs Abstención

28) Participación ciudadana

29) Corrupción

30) Infraestructuras

31) Plan Hidrográfico Nacional

32) Manipulación informativa - medios públicos 
33) Manipulación informativa - medios privados

34) Debates electorales

35) Política internacional

36) Cultura

37) Canon digital

38) Sociedad de la información / Nuevas tecnologías

39) Políticas de igualdad / Derechos sociales

40) Ley del aborto

41) Utilización electoralista de fondos públicos

42) Agricultura

43) Unión Europea

44) Problemas urbanísticos

45) Industria

46) Medio Ambiente

47) Memoria Histórica

48) Crispación

49) Justicia

50) Iglesia, relaciones con la iglesia / catolicismo

51) Otros

52) No se aplica / temas ajenos a la campaña electoral

53) Cese definitivo de la violencia

54) Candidatos (personalidad, cualidades)

55) Política interna de partido

56) Anécdotas. Aspectos no políticos de la campaña (cuestiones estéticas, frivolidades, etc.).

57) Resultados electorales 